\title{
Dynamic Modeling with Experimental Calibration for the Syngas Production from Biomass Fixed-bed Gasification
}

\author{
Xin $\mathrm{He}^{1}$, Qiang $\mathrm{Hu}^{1}$, Haiping Yang ${ }^{2}$, Christine Annette Shoemaker ${ }^{1}$, and Chi-Hwa Wang ${ }^{1}$ \\ ${ }^{1}$ National University of Singapore \\ ${ }^{2}$ Huazhong University of Science and Technology
}

October 18, 2020

\begin{abstract}
In this paper, a dynamic biomass gasification model was developed based on the hybrid peripheral fragmentation and shrinkingcore (HPFS) model. To improve the accuracy of syngas generation transient prediction, the chemical kinetic model was trained using global surrogate optimization techniques. The pre-exponential factors of kinetic reactions are calibrated under non-catalytic conditions, employing experimental transient data of syngas generation rate and compositions under different temperatures and gasifying agents. The DYCORS and GOMORS were employed as the numerical solvers for finding the global optimum solution of the pre-exponential factors. The calibrated kinetic models based on both single-objective and multiobjective approaches have been validated by experimental data in four different biomass gasification scenarios. The calibrated kinetic model shows an over 95\% decrease in terms of integrated squared error (ISE)-based model mismatch when compared to the original kinetic model.
\end{abstract}

\section{Hosted file}

Manuscript.pdf available at https://authorea.com/users/368161/articles/487400-dynamicmodeling-with-experimental-calibration-for-the-syngas-production-from-biomass-fixed-bedgasification 